\title{
Pre-conceptual Core Design of a Small Modular Fast Reactor \\ Cooled by Supercritical $\mathrm{CO}_{2}$
}

\author{
Baolin Liu ${ }^{1}$, Liangzhi Cao ${ }^{1}$, Hongchun $\mathrm{Wu}^{1}$, Xianbao Yuan ${ }^{*, 1,2}$, Kunpeng Wang ${ }^{3}$ \\ ${ }^{1}$ School of Nuclear Science and Technology, Xi'an Jiaotong University, No 28,Xianning West \\ Road, Xi'an, Shaanxi 710049, PR China \\ ${ }^{2}$ College of Mechanical \& Power Engineering, China Three Gorges University, No 8, Daxue road, \\ Yichang, Hubei 443002, PR China \\ ${ }^{3}$ Nuclear and Radiation Safety Center, P.O. BOX 8088, Beijing 100082, China
}

\begin{abstract}
s

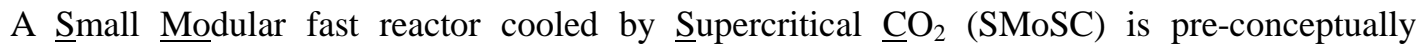
designed through three-dimensional coupled neutronics/thermal-hydraulics analysis. The power rating of the $\mathrm{SMoSC}$ is designed to be $300 \mathrm{MW}_{\text {th }}$ to meet the energy demand of small electrical grids. The excellent thermal properties of supercritical $\mathrm{CO}_{2}\left(\mathrm{~S}-\mathrm{CO}_{2}\right)$ are employed to obtain a high thermal efficiency of about $40 \%$ with an electric output of 120 MWe. MOX fuel is utilized in the core design to improve fuel efficiency. The tube-in-duct (TID) assembly is applied to get lower coolant volume fraction and reduce the positive coolant void reactivity. According to the coupled neutronics/thermal-hydraulics calculations, the coolant void reactivity is kept negative throughout the whole core life. With a specific power density of $9.6 \mathrm{~kW} / \mathrm{kg}$ and an average discharge burnup of $70.1 \mathrm{GWd} / \mathrm{tHM}$, the SmoSC can be operated for 20 Effective Full Power
\end{abstract}

*Corresponding author.

Email address: ztsbaby@163.com. 
Years (EFPYs) without refueling.

Keywords: small modular reactor, fast reactor, $\mathrm{S}-\mathrm{CO}_{2}$, tube-in-duct.

\section{Introduction}

One possible way to meet the energy demand is through the development of small modular reactors (SMRs) (Kessides 2012; Smith 2010) with an electric power of 300 MW or less. SMRs have a number of advantages against conventional large reactors. The most important advantage is its low cost for construction and operation. This makes them beneficial in providing electric power to areas with small, limited, or distributed electricity grid system as well as for countries with limited financial resources for investment in large nuclear power plants. Besides, SMRs can be placed in remote or inland areas where it is not possible to site conventional water cooled reactors (Vujić J. et al., 2012). For this reason, SMRs with a long refueling interval are preferred to be developed.

In recent years, $\mathrm{S}-\mathrm{CO}_{2}$ has been considered as the coolant for fast reactor design. By taking advantage of the low compressibility of $\mathrm{CO}_{2}$ near its critical point, the $\mathrm{S}-\mathrm{CO}_{2}$ recompression cycle can achieve high efficiency with relatively low temperature (Pope M.A., 2006; Hejzlar, et al., 2002). This will be beneficial to improve the economics of SMR power plant.

Based on these ideas, a S-CO $\mathrm{CO}_{2}$ cooled Fast Reactor with a power rating of $300 \mathrm{MW}_{\mathrm{th}}$, which is with the assumed thermal efficiency of $40 \%$ resulting in $\sim 100 \mathrm{MWe}$ has been studied. The SMoSC is aimed to be designed for local small grids and run for a long period without frequent refueling. To achieve these strategic goals, there are two design requirements proposed for the SMoSC core design: long refueling interval with small burnup reactivity swing and negative 
coolant void reactivity. The heat transport system would be based on a $\mathrm{S}-\mathrm{CO}_{2}$ Brayton cycle power conversion system, and the overall plant heat transport system would be similar to the system in Ref.( Handwerk C.S., 2007).

Several fuel options and the innovative $\mathrm{S}-\mathrm{CO}_{2}$ cooled fast reactor technologies have been investigated or are being studied for improving the overall core performance and safety features, which include a compact core concept with TID assemblies and advanced shielding material, advanced cladding materials for high burnup fuel and high temperature, etc. (Pope M.A., 2004). The SMoSC core adopts innovative gas fast reactor technologies and advanced structural and cladding materials, so that the system could have favorable economics and safety features. The main assembly parameters are selected for maximizing the refueling interval with small excess reactivity, minimizing the material temperature and coolant void reactivity. The enrichment zoning strategy which allows for 20 years refueling interval with a minimal burnup reactivity swing and a flat power distribution, is applied for the SMoSC core.

The remaining part of this paper is organized as follows. In Sec. 2, the coupled neutronics/thermal-hydraulics computational method is introduced. In Sec. 3, the design criteria, fuel assembly design, control assembly design, reflector material selection and enrichment zoning strategy are introduced. In Sec. 4, the optimized core design is presented. The conclusions are drawn in Sec. 5.

\section{Core design method}

The flow chart of the coupled calculation is shown in Fig. 1. The three-dimensional coupled neutronics/thermal-hydraulics analysis code package developed at Xi'an Jiaotong University was 
employed in this study. The neutronics calculations were carried out based on the PIJ and CITATION codes (Fowler T.B. et al., 1971), and the thermal-hydraulic analysis was performed based on the single channel analysis code. 


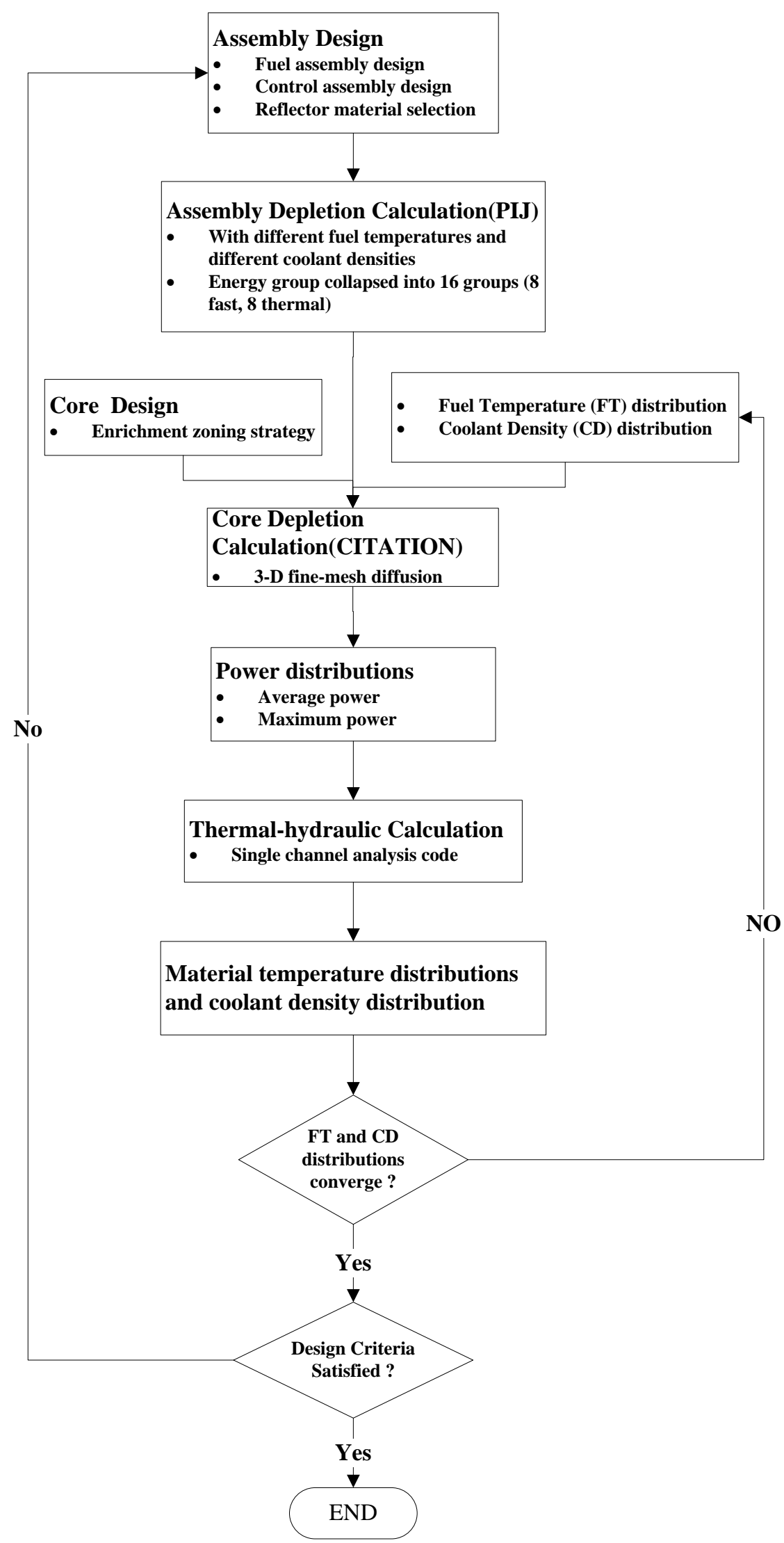

Fig. 1. Flow chart of core calculation and design 


\subsection{Neutronics calculations}

As shown in Fig. 1, two steps were involved in the neutronics calculations. First, the two-dimensional assembly calculations were performed to generate the cross sections for core analysis. The assembly calculations were carried out based on a code named PIJ, which is a code using hyper-fine group resonance method and collision probability method for neutron transport calculations. The PIJ code was developed based on the SRAC code system (Okumura K. et al., 2007). Cross sections were taken from the 107-group library based on the JENDL-3.3 data library. In the core analysis of fast reactors, larger number of the energy group is required because of complex neutron spectrum. From previous experience (Chin M.R., et.al., 2013), it was concluded that no less than 10 neutron energy groups would get high accurate results for fast reactor analysis. Considering the balance between computational cost and accuracy, the 107 energy-group cross sections were collapsed into 16 ( 8 thermal and 8 fast) coarse groups, as a function of $\mathrm{CO}_{2}$ density, fuel temperature and burnup. After assembly depletion calculations, the channel power distribution in an assembly, the cross sections and diffusion coefficients were obtained. The core depletion calculation started based on the three-dimensional multi-group diffusion code CITATION. With the channel power distribution obtained during the assembly depletion and the assembly power distribution obtained through the core depletion calculation, we could get the maximum fuel power and the average power of the assembly for thermal-hydraulics calculations.

\subsection{Thermal-hydraulic calculations}

As there is no cross flow between coolant channels in the tube-in-duct design, the single channel model can be used for thermal-hydraulics calculations. The thermal-hydraulic calculations 
were performed with an in-house code based on single-channel model (Pope M.A., 2006). There is no phase change of supercritical $\mathrm{CO}_{2}$ coolant in this core design, and the coolant is treated as single-phase flow. Heat transfer coefficients were determined by the relationship as follows (Gnielinski, V., 1975).

$$
N u=h \frac{D_{c}}{k} \frac{(f / 8)(\operatorname{Re}-1000) \operatorname{Pr}}{1+12.7 \sqrt{(f / 8)\left(\operatorname{Pr}^{2 / 3}-1\right)}}\left[1+\left(\frac{D_{c}}{L_{h}}\right)^{2 / 3}\right] \mathrm{K}
$$

Where $N u$ is Nusselt number, $h$ is the heat transfer coefficient, $k$ is the coolant conductivity evaluated at the bulk temperature, $D_{c}$ is the coolant channel diameter, $R e$ is the Reynolds number, $\operatorname{Pr}$ is the Prandtl number evaluated at the bulk fluid temperature, and $L_{h}$ is the heated length (distance traveled past the onset of heating). $f$ is the friction factor, which is the smooth-wall isothermal Darcy(or Moody) friction factor given as follows(Gnielinski, V., 1975).

$$
f=\frac{1}{(1.82 \log (\mathrm{Re})-1.64)^{2}}
$$

The $\mathrm{K}$ term is given as follows (Gnielinski, V., 1975), which accounts for the fluid having different properties at the wall temperature than at the bulk temperature.

$$
K=\left(\frac{T_{\text {bulk }}}{T_{\text {wall }}}\right)^{0.45}
$$

Where $\mathrm{K}$ is a factor used to capture the heated wall effect, $T_{\text {wall }}$ is the temperature of the cladding at the surface in contact with coolant and $T_{b u l k}$ is the bulk coolant temperature. This particular expression for the factor $\mathrm{K}$ is meant to be used for a gas coolant only.

And then we can get the $T_{\text {wall }}$, which is an iterative solution.

$$
T_{\text {wall }}=T_{\text {bulk }}+\frac{q_{\text {wall }}}{h}
$$


Where $q_{\text {wall }}$ is the heat flux at the clad surface in contact with coolant.

Each fuel assembly was treated as one channel. The single-channel calculation was carried out with two kinds of power: one was the maximum fuel power for getting maximum cladding surface temperature and maximum fuel temperature. The other was the average power of the assembly for getting coolant density distribution and coolant outlet temperature. With the power distributions calculated by core depletion calculation, the average and maximum power of each assembly could be obtained at all burnup steps. Considering the maximum power of each assembly through the whole core life, the core coolant flow rate in each assembly could be searched to satisfy the thermal-hydraulic design criteria. Once the flow rate distribution was obtained, it would not be changed throughout the core life. With the flow rate distribution, coolant density distribution, outlet temperature and pressure drop at each burnup step could be calculated using the average power of each assembly.

In the coupled neutronics/thermal-hydraulics calculation, as indicated in Fig. 1, the calculated coolant density distribution is fed back as input to the neutronics code and the process is repeated until the convergence.

\section{Core design}

In this study, the following parameters need to be optimized:

1) the assembly parameters(cladding/duct wall thickness, the coolant tube diameter, the coolant to fuel ratio and the assembly size);

2) the number of assemblies;

3) enrichment zoning strategy ; 
4) the axial and horizontal core sizes.

The number of the coolant channel in the fuel assembly is the same as the number in the Ref.(Pope M.A., 2004), which is 91. After the cladding/duct wall thickness is decided, the coolant to fuel ratio would be decided by the coolant tube diameter and the assembly size.

For the fuel assembly design, the main problem is how to decide the values of the coolant tube diameter and the assembly size. In this study, the values of the coolant tube diameter and the assembly size were selected based on the core calculation with the values of the number of assemblies and the axial and horizontal core sizes and the enrichment zoning strategy.

During the calculations, firstly, the assembly initial size and the coolant tube initial diameter were set. And then a series of the combination of the number assemblies and the enrichment zoning strategy were checked whether or not to satisfy the design criteria based on core calculations. The core multiplication factor, reactivity coefficient and the steady-state thermal-hydraulic performance would be obtained. Finally, we would check the design criteria.

If the design criteria were satisfied, the values of the coolant tube diameter and the assembly size, the enrichment zoning strategy and the number assemblies were decided.

If the design criteria were not satisfied, we could adjust three parameters: the coolant tube diameter, the enrichment zoning strategy and the number assemblies (and keep the core size as small as possible). If the design criteria still could be not satisfied, then the assembly initial size would be adjusted and the process would be repeated until the design criteria were satisfied.

Since the assembly size was checked in ascending order, the core design with "the largest power density" would also be obtained. In the iterative calculations, the assembly parameters, the number of assemblies, enrichment zoning strategy (including the number of the fuel assembly in 
each enrichment zone) and the axial and horizontal core sizes had been optimized.

\subsection{Design goals}

In order to reduce the engineering implementation difficulty, the core is operated at the pressure of $14 \mathrm{MPa}$. The average inlet and outlet temperatures are $300{ }^{\circ} \mathbf{C}$ and $500{ }^{\circ} \mathbf{C}$ respectively. The thermal efficiency is $40 \%$, according to the relationship between turbine inlet temperature and thermal efficiency given in the previous studies (Angelino G., 1969; Dostal V., 2004). The thermal output scale is $300 \mathrm{MW}_{\text {th }}$, thus the power scale corresponds to an electric output is about 120 MWe. For the SMoSC core concept, all fuel assemblies are replaced with fresh fuels every 20 years.

The following design criteria are considered to ensure core safety:

- Negative void reactivity throughout the whole life;

- Maximum cladding temperature less than $800{ }^{\circ} \mathbf{C}$;

- Maximum fuel temperature less than $1800^{\circ} \mathbf{C}$;

- Total core pressure drop less than $400 \mathrm{kPa}$;

- Burnup reactivity swing less than or equal to about $1000 \mathrm{pcm}$.

The material temperature limitations (Pope M.A., 2006) are determined to ensure the fuel integrity at both normal operation and abnormal transients. Pressure drop across the core is important, because it directly impacts the compressor work and thus has direct bearing on the thermodynamic efficiency of the power cycle (Feher E. G., 1967). In order to obtain the thermal efficiency of $40 \%$, a core pressure drop limit of $400 \mathrm{kPa}$ at full power is set. For easy control of the core reactivity, the burnup reactivity swing should be less than or equal to about $1000 \mathrm{pcm}$. 


\subsection{Fuel assembly design}

In this study, the TID assembly wherein the assembly consists of a can with coolant tubes is chosen as the fuel assembly. This kind of fuel assembly could provide two benefits. First, the coolant volume fraction in the TID assembly could be lower than that of the pin-type assembly. This would reduce the effect of spectral hardening resulting from the possible loss of coolant accident (LOCA). Also, the TID assembly has high fuel volume fraction, which would be valuable for choosing dioxide fuels with acceptable reactivity-limited burnup. While dioxide fuels have lower density than carbide fuels or nitride fuels, this would attract interest because dioxide fuels are not chemically reactive with $\mathrm{CO}_{2}$ (Pope M.A., 2004).

The horizontal cross-section of the assembly is shown in Fig. 2. Axial reflector and shielding materials are placed at the top and bottom of the assembly inside the same cell volume envelope as the fuel. Coolant enters the assembly from the bottom through a debris filter and flows into the coolant channels. The area surrounding the coolant channels inside the assembly is filled with MOX fuel $\left(\mathrm{PuO}_{2}\right.$ is blended with depleted uranium). The fraction of Pu isotopes are kept the same as the PWR (initial fuel enrichment 3.2\%) discharged fuel with a burnup of $33 \mathrm{MWd} / \mathrm{kgHM}$. The plutonium vector is shown in Table 1. In the study, the core burnup is smaller than that of the large power core design (Handwerk C.S., 2007). The number of the coolant channel in the fuel assembly is 91 , the cladding thickness is $0.7 \mathrm{~mm}$ which is a conservative value, and the size of the gap between cladding and fuel is $0.07 \mathrm{~mm}$ (Pope M.A., 2006). As for the materials of the cladding and duct wall, the ODS MA956 (one kind of stainless steel) is selected mainly due to its superior creep resistance to other kind of stainless steel, such as stainless steel 316 (Peckner, et. al., 1977;

Kimura, et. al., 2004; Pope M.A.,2006). 


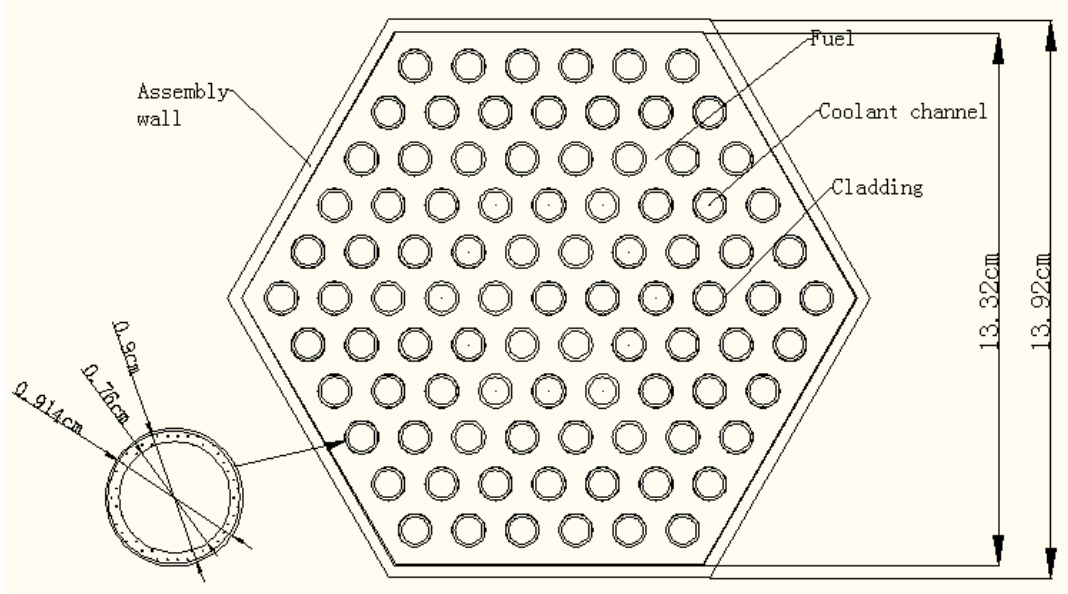

Fig.2. Horizontal cross-section of the TID fuel assembly

Table 1. Plutonium vector at the beginning of core life

\begin{tabular}{ccccc}
\hline \multicolumn{5}{c}{ Plutonium (kg nuclide per kg plutonium) } \\
\hline $\mathrm{Pu}-238$ & $\mathrm{Pu}-239$ & $\mathrm{Pu}-240$ & $\mathrm{Pu}-241$ & $\mathrm{Pu}-242$ \\
0.013 & 0.644 & 0.211 & 0.098 & 0.034 \\
\hline
\end{tabular}

In order to increase the neutron capture probability during a LOCA and reduce the coolant void reactivity, the thickness of the assembly duct wall is set to $0.3 \mathrm{~cm}$, larger than the reference value of $0.2 \mathrm{~cm}$ (Pope M.A., 2006; Handwerk C.S., 2007). There exists a $0.15 \mathrm{~cm}$ thick coolant gap between assemblies.

In order to maximize the core life and keep the material temperature below limits, after the iterative calculations according to the core design chart shown in Fig. 1, the assembly pitch and the coolant tube cladding inner diameter are selected to be $13.92 \mathrm{~cm}$ and $0.76 \mathrm{~cm}$ respectively.

\subsection{Control assembly design}

The control assembly is required to introduce sufficient reactivity worth to bring the reactor from any operation conditions to sub-critical state. For the SMoSC, $\mathrm{B}_{4} \mathrm{C}$ enriched to $90 \mathrm{w} / \mathrm{o}$ is chosen as the neutron absorber material (Pope M.A., 2004). The horizontal cross-section of the 
control assembly when the rods are inserted is shown in Fig. 3. The center region contains a bundle of absorber rods with coolant flowing around them. The number of the absorber rod is 37 . The absorber rods can be withdrawn upward from the core. After these absorber rods are removed, the center region will be filled with coolant. In order to ensure enough shutdown margin, the radius of the absorber rod is set to be $0.4 \mathrm{~cm}$, and the cladding thickness of the rod is $0.5 \mathrm{~mm}$. The material around the bundle of absorber rods is ODS MA956 due to its excellent oxidation resistance, which can also increase the neutron absorption during a LOCA.

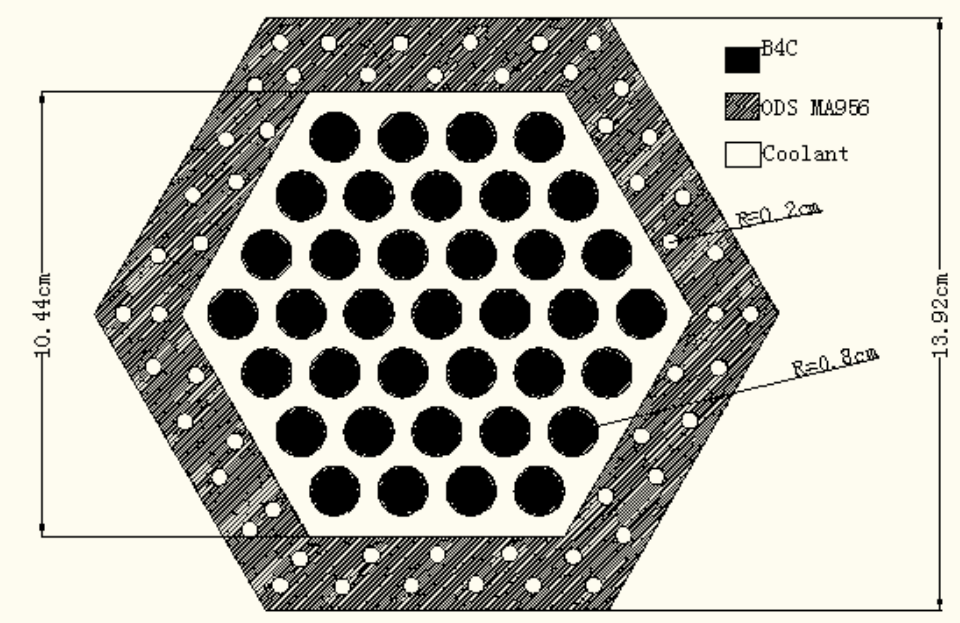

Fig. 3. Horizontal cross-section of control assembly

\subsection{Reflector material}

In a gas cooled fast reactor, the LOCA accident represents one of the most limiting accident scenarios, because significant positive reactivity is typically inserted upon core voiding. After the loss of pressure, the introduction of reactivity from the loss of coolant in a gas cooled fast reactor is much faster than that in other fast reactors. The coolant void reactivity limit in the gas cooled fast reactor is more stringent. Hence, if a reactor can be designed so that the negative reactivity is inserted while coolant voiding occurs, the reactor will be much more inherently safe. 
In this study, the titanium and $\mathrm{S}-\mathrm{CO}_{2}$ are considered as the alternative radial reflector materials. For the calculation module of the $\mathrm{S}-\mathrm{CO}_{2}$ reflector, the reflector region is filled only with S- $\mathrm{CO}_{2}$ without any structure material. And for the calculation module of the titanium reflector, the titanium assembly with the $\mathrm{S}-\mathrm{CO}_{2} 20 \%$ by volume was considered. The core shown in Fig. 4 with these two types of radial reflector material was calculated. Coolant was assumed to be voided by $\sim 100 \%$ (coolant density changed from $0.1 \mathrm{~g} / \mathrm{cc}$ to $0.002 \mathrm{~g} / \mathrm{cc}$ ).In Fig.4, A stands for 10, B stands for 15 and $\mathrm{C}$ stands for 20. From the results shown in Fig. 5, we can see that the $\mathrm{S}-\mathrm{CO}_{2}$ as the radial reflector obtained smaller coolant void reactivity than the titanium. The reason is that the $\mathrm{S}-\mathrm{CO}_{2}$ can enhance the radial leakage and reduce the coolant void reactivity in a LOCA accident. So in this study, the $\mathrm{S}-\mathrm{CO}_{2}$ is chosen as the radial reflector material. This would ensure that upon a LOCA and concurrent coolant voiding, the reflector would be void (Waltar, et al., 1981). In order to ensure the critical state of the core, the titanium (Handwerk C.S., 2007; Yu K., 2003, Ashley, 2003) is chosen as the axial reflector. And in the core calculation module, the axial reflector thickness is $10 \mathrm{~cm}$.

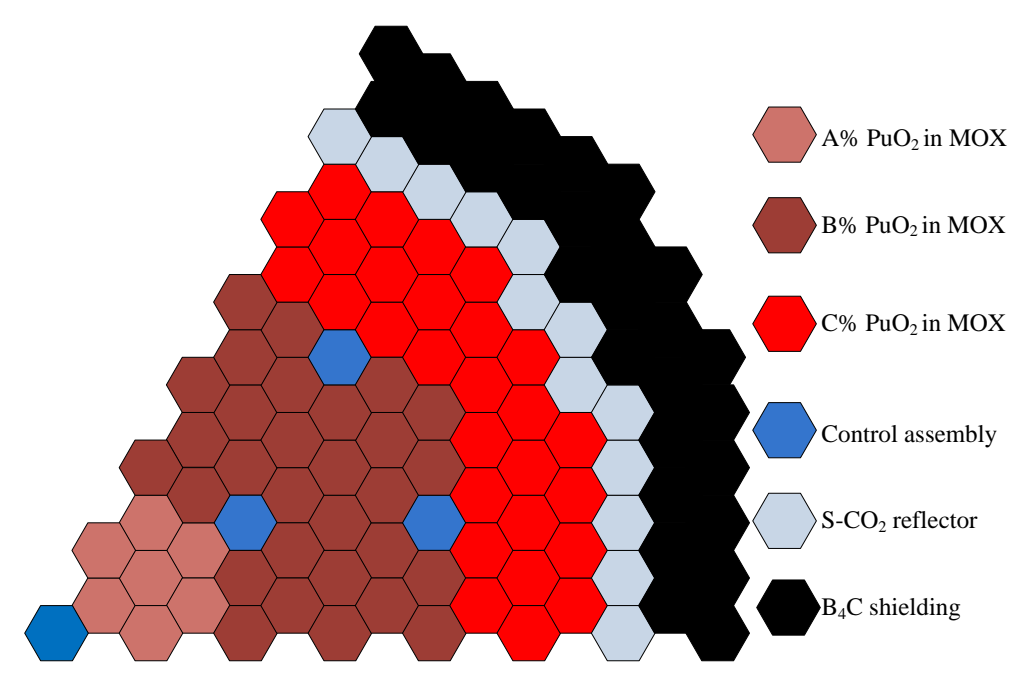

Fig. 4. Radial Cross Section of the core $\left(1 / 6^{\text {th }}\right.$ Core Map) 


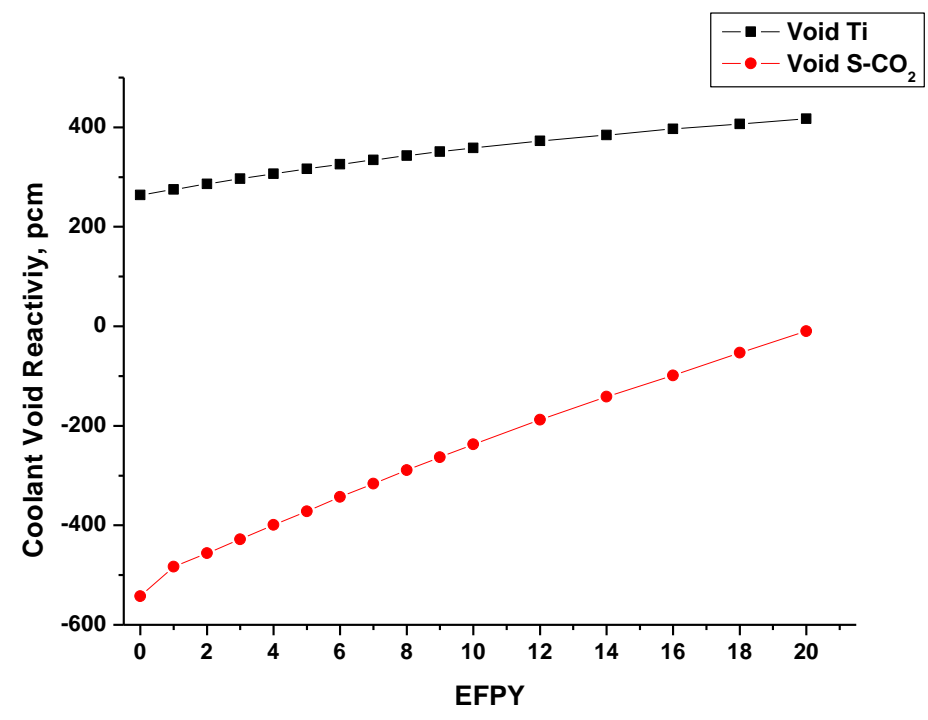

Fig. 5. Coolant void reactivity with different radial reflector materials

\subsection{Enrichment zoning strategy}

For the consideration of flattening the power distribution, the high leakage fuel loading pattern strategy is employed. The active core region would be divided into several different enrichment zones: lower $\mathrm{PuO}_{2}$ volume percent for inner core and higher $\mathrm{PuO}_{2}$ volume percent for outer core.

The radial layout of the core is shown in Fig. 4, and the active core region is divided into three parts. Each part stands for a value of volume percent of $\mathrm{PuO}_{2}$ in $\mathrm{MOX}(\mathrm{A} \% / \mathrm{B} \% / \mathrm{C} \%)$. A sensitivity analysis on the enrichment zoning has been performed with four cases given in Table 2 .

Table 2. Enrichment Zoning Scheme

\begin{tabular}{lcccc}
\hline & \multirow{2}{*}{ Active core height /m } & \multicolumn{3}{c}{ Fuel Enrichment (\%) } \\
\cline { 2 - 5 } & & Zone A & Zone B & Zone C \\
\hline Case1 & 1.2 & 8 & 14 & 20 \\
Case2 & 1.2 & 8 & 15 & 20 \\
Case3 & 1.1 & 10 & 15 & 20 \\
Case4 & 1.0 & 10 & 15 & 20 \\
\hline
\end{tabular}

Fig. 6 shows the multiplication factors versus EFPYs of the typical cases described in Table 1. 
From the results of the case 1 and case 2 shown in Fig. 8 and Table 2, we can see that: 1) the more amount of U-238 in the core means the higher breeding ratio. 2) The core with the less amount of $\mathrm{Pu}-239$ could obtain a smaller coolant void because the effective fission neutrons of $\mathrm{Pu}-239$ would increase when the neutron spectrum is hardened in the condition of the coolant void. 3) The burnup reactivity swing of case 1 is the largest due to its highest breeding ratio of 1.158 .

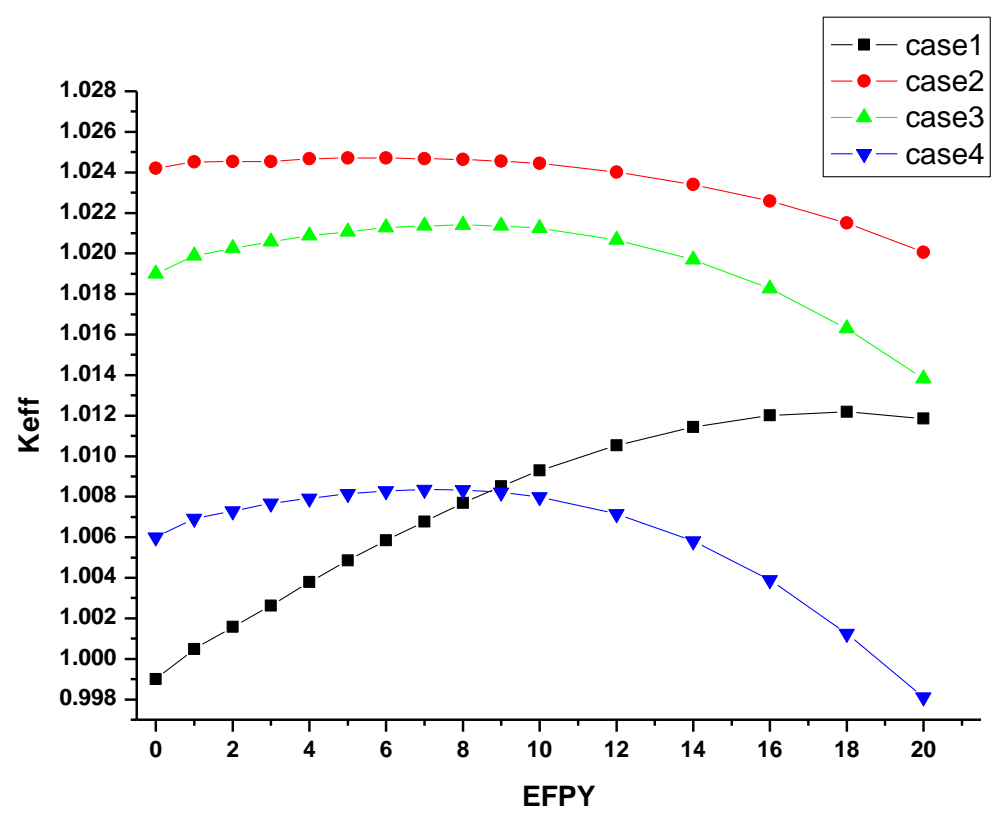

Fig. 6. Multiplication factor versus EFPYs

The core with a smaller active core height would cause higher neutron leakage than that with a higher active core height. The higher neutron leakage favors the smaller coolant void reactivity. As can be seen from the results of the case 3 and the case 4 shown in Table 3 , case 4 with a smaller active core height obtains a smaller coolant void reactivity than case 3.

Table 3. Breeding ratio and the coolant void reactivity of the typical cases

\begin{tabular}{ccccc}
\hline & $\begin{array}{c}\text { Breeding Ratio } \\
(\mathrm{BOL})\end{array}$ & $\begin{array}{c}\text { Coolant void } \\
\text { reactivity(BOL) } \\
/ \mathrm{pcm}\end{array}$ & $\begin{array}{c}\text { Coolant void } \\
\text { reactivity(MOL) } \\
/ \mathrm{pcm}\end{array}$ & $\begin{array}{c}\text { Coolant void } \\
\text { reactivity(EOL) } \\
/ \mathrm{pcm}\end{array}$ \\
\hline Case 1 & 1.15794 & -681.4 & -365.9 & -93.2 \\
Case 2 & 1.11688 & -585.1 & -236.9 & -48.5 \\
\hline
\end{tabular}




\begin{tabular}{llllc}
\hline Case 3 & 1.14658 & -542.7 & -237.5 & -9.8 \\
Case 4 & 1.11462 & -569.6 & -265.0 & -14.2 \\
\hline
\end{tabular}

The high leakage fuel loading pattern strategy would increase the neutron leakage and as a result the core would have small core multiplication factor at the BOL. However, the breeding ratio would be higher in the inner core regions because there is more U-238 which would be converted to $\mathrm{Pu}-239$. Due to the high core breeding ratio as the burning zone would move into the core center, the core could maintain criticality for a long time without refueling while the burnup reactivity swing would not be significant.

\section{Optimized Core Design}

In the results of the four typical cases described in Table 2, the case 4 obtained the largest power density because of its smallest core size, but it would turn into the subcritical state at the EOL. Case 3 would keep critical state at the EOL, but its size needed to be optimized. Based on this analysis, an optimized core design was obtained. The radial layout of the optimized SMoSC core is shown in Fig. 4 and the axial cross sections of the calculation module are depicted in Fig. 7. In Fig.4, A stands for 10, B stands for 15 and C stands for 20. The active height of the core is 105 $\mathrm{cm}$ which is between the height of case 3 and that of case 4 . The core consists of 360 fuel assemblies, 19 control assemblies and 162 radial shielding assemblies. The active core region is divided into three enrichment zones: 36 assemblies with $10 \%$ volume percent $\mathrm{PuO}_{2}$ in $\mathrm{MOX}$ for inner core, 162 assemblies with $15 \%$ volume percent $\mathrm{PuO}_{2}$ in $\mathrm{MOX}$ for middle core and 162 assemblies with $20 \%$ volume percent $\mathrm{PuO}_{2}$ in $\mathrm{MOX}$ for outer core. 


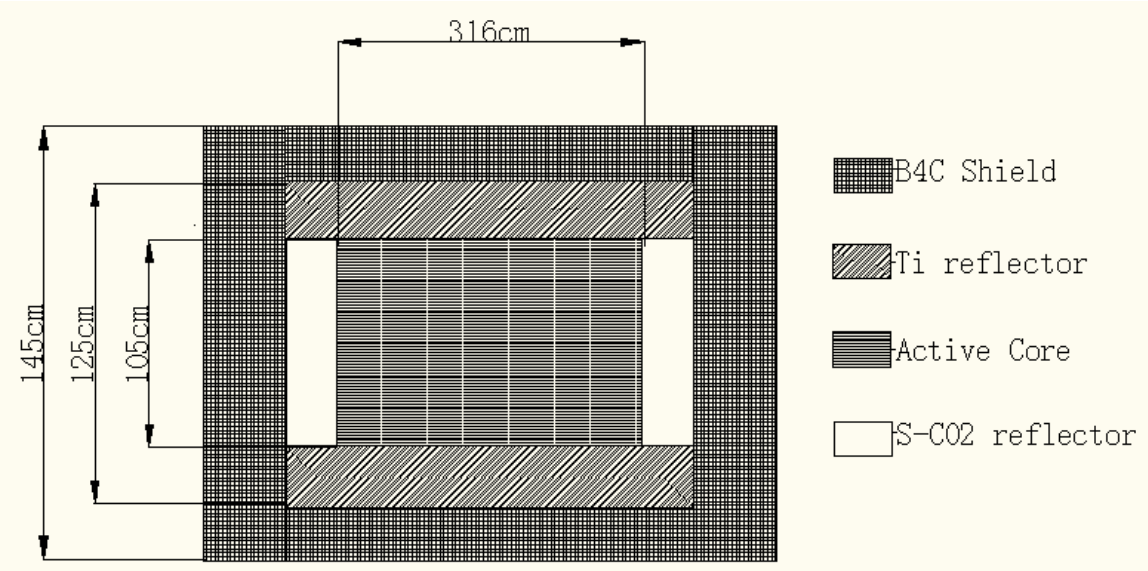

Fig. 7. Axial Cross Section of the SMoSC

The primary design parameters and core performance parameters of the SMoSC are summarized in Table 4.

Table 4.Main Parameters of the SMoSC

\begin{tabular}{ll}
\hline \multicolumn{1}{c}{ Parameters } & \multicolumn{1}{c}{ Values } \\
\hline Core thermal power $\left(\mathrm{MW}_{\text {th }}\right.$ ) & 300 \\
Cycle length (year) & 20 \\
System Pressure $(\mathrm{MPa})$ & 14 \\
Thermal efficiency & $40 \%$ \\
Fuel form & $\mathrm{MOX}$ \\
Fuel Assembly Description & Tube-in-Duct \\
Number of the Fuel Assembly & 360 \\
Number of the Control Assembly & 19 \\
Effective Active Core Diameter (cm) & 316 \\
Active Core Height (cm) & 105 \\
Initial heavy metal inventory (t) & 31.23 \\
Average power density (W/cc) & 36.45 \\
Specific power density (MW/tHM) & 9.6 \\
Number of the assemblies with 10\% volume & 36 \\
percent PuO $\mathrm{P}_{2}$ in MOX & \\
Number of the assemblies with 15\% volume & 162 \\
percent $\mathrm{PuO}_{2}$ in MOX & \\
Number of the assemblies with 20\% volume & 162 \\
percent $\mathrm{PuO}_{2}$ in MOX & \\
Number of the radial shielding assemblies & 162 \\
\hline
\end{tabular}

The high leakage fuel loading pattern strategy and the $\mathrm{S}-\mathrm{CO}_{2}$ coolant radial reflector increase the radial neutron leakage. As a result, the core has a small multiplication factor of 1.013 at the 
BOL. However, due to the high breeding ratio of 1.115 at the BOL, the core can maintain criticality for a long time without refueling. The resulting burnup reactivity swing is $872 \mathrm{pcm}$, as shown in Fig. 8.

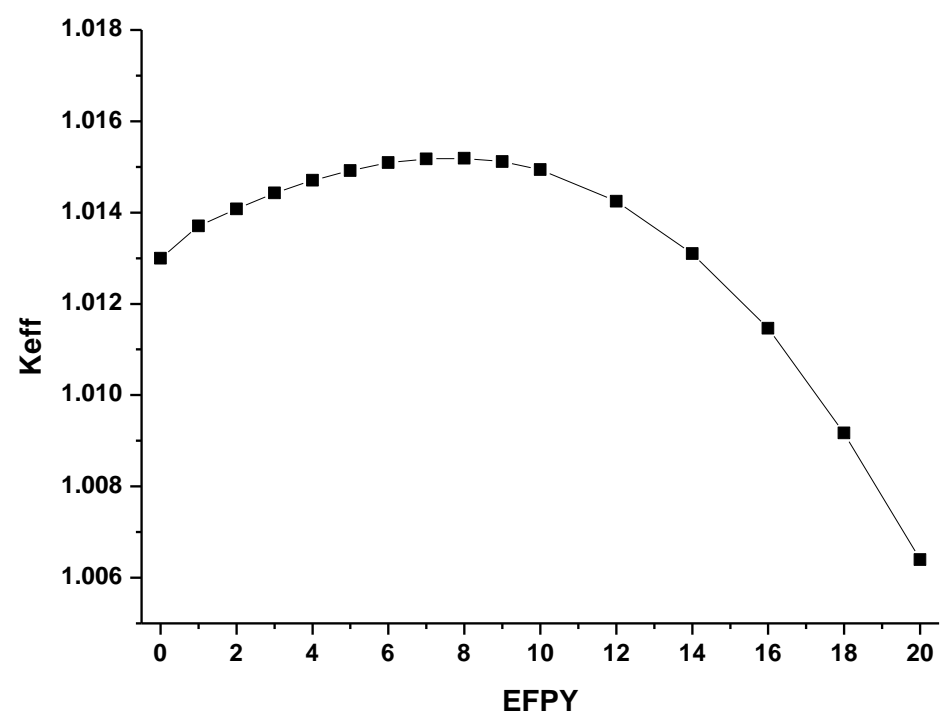

Fig. 8 Core multiplication factor versus EFPYs

\subsection{Power distribution}

The radial power distributions at the BOL, MOL and EOL are shown in Fig.9. The radial power peaking factors is defined as the ratio of the maximum fuel assembly power density to the average fuel assembly power density in the core. The radial power peaking factors at the BOL, MOL and EOL are 1.435, 1.359 and 1.410, respectively.

As shown in Fig. 9, the power density of the inner fuel regions is small at the BOL and the outer fuel regions make more contribution to the core power. As the core operation time goes by, the maximum power zone moves toward the core center. This should be owed to the high leakage fuel loading pattern strategy, which increases the radial neutron leakage and also flatten the radial 
power distribution. This could also flatten the burnup distribution and increase fuel efficiency to a certain extent.

At the BOL, there is more amount of $\mathrm{Pu}-239$ in outer fuel regions than that in inner fuel regions. While the fact that more amount of U-238 in the inner region would be converted into Pu-239 due to the high leakage enrichment zoning strategy makes the balance between the increase in the fission of $\mathrm{Pu}-239$ in the inner region and the decrease in the fission of $\mathrm{Pu}-239$ in the outer region, and so the burning zone moves into the inner regions throughout the core life.

Because of the changing power profile in the core over the lifetime, the cladding temperature, the fuel temperature and the coolant outlet temperature distributions would also be changing through the core operation life.

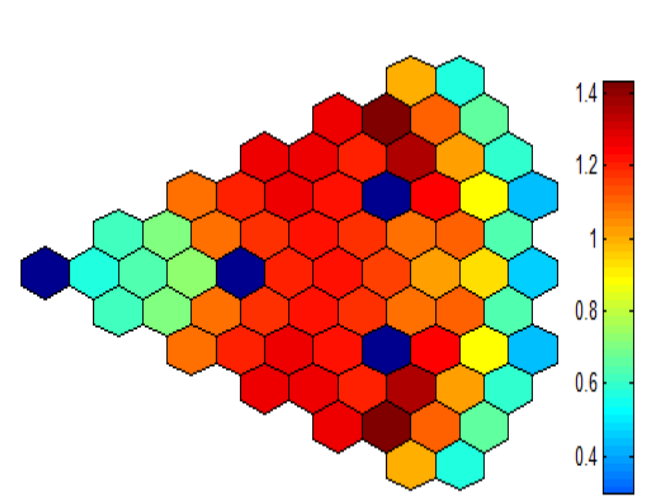

BOL

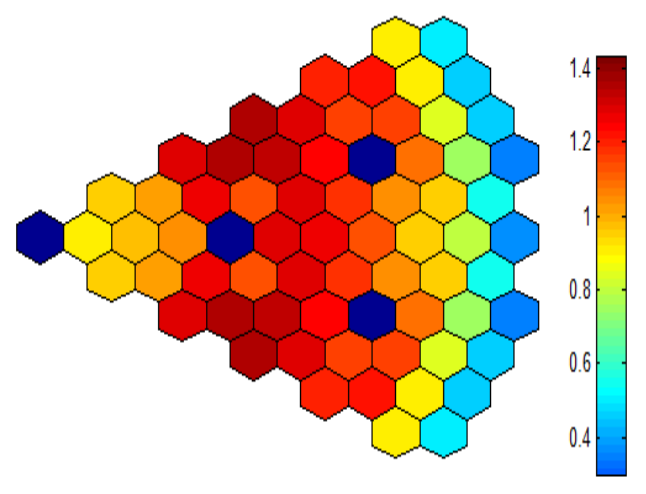

MOL

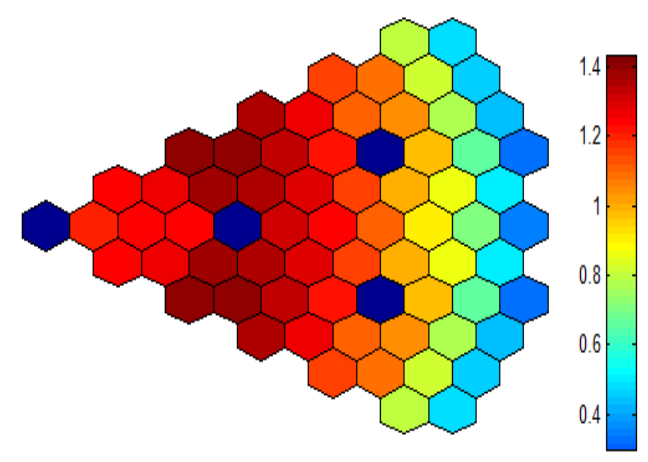

EOL

Fig. 9. Normalized radial power distribution $\left(1 / 6^{\text {th }}\right.$ core $)$ 


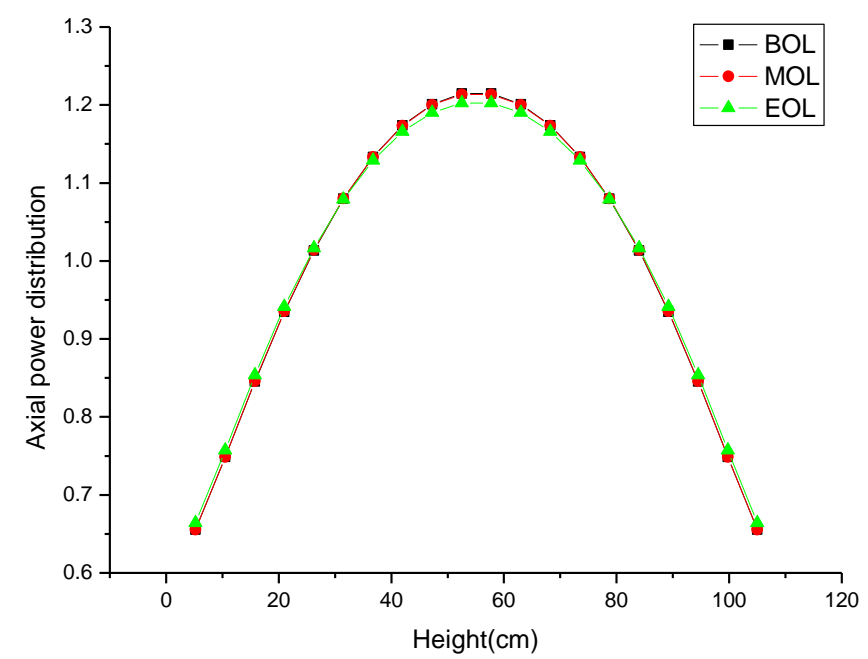

Fig. 10. Normalized axial power distribution

The flat core design with the height to diameter ratio of 0.332 also increases the axial neutron leakage, and the power distribution swing was expressed mainly in the radial direction due to the small height to diameter ratio. As shown in Fig. 10, the axial power distribution has a small swing throughout the core life.

\subsection{Burnup distribution}

In order to meet the safety criteria and achieve negative coolant void reactivity through the core operating time, both the power density and the discharged burnup are kept low. The average discharged burnup is $70.1 \mathrm{GWd} / \mathrm{tHM}$ and the peak discharged burnup is $99.16 \mathrm{GWd} / \mathrm{tHM}$, which is shown in Fig. 11 


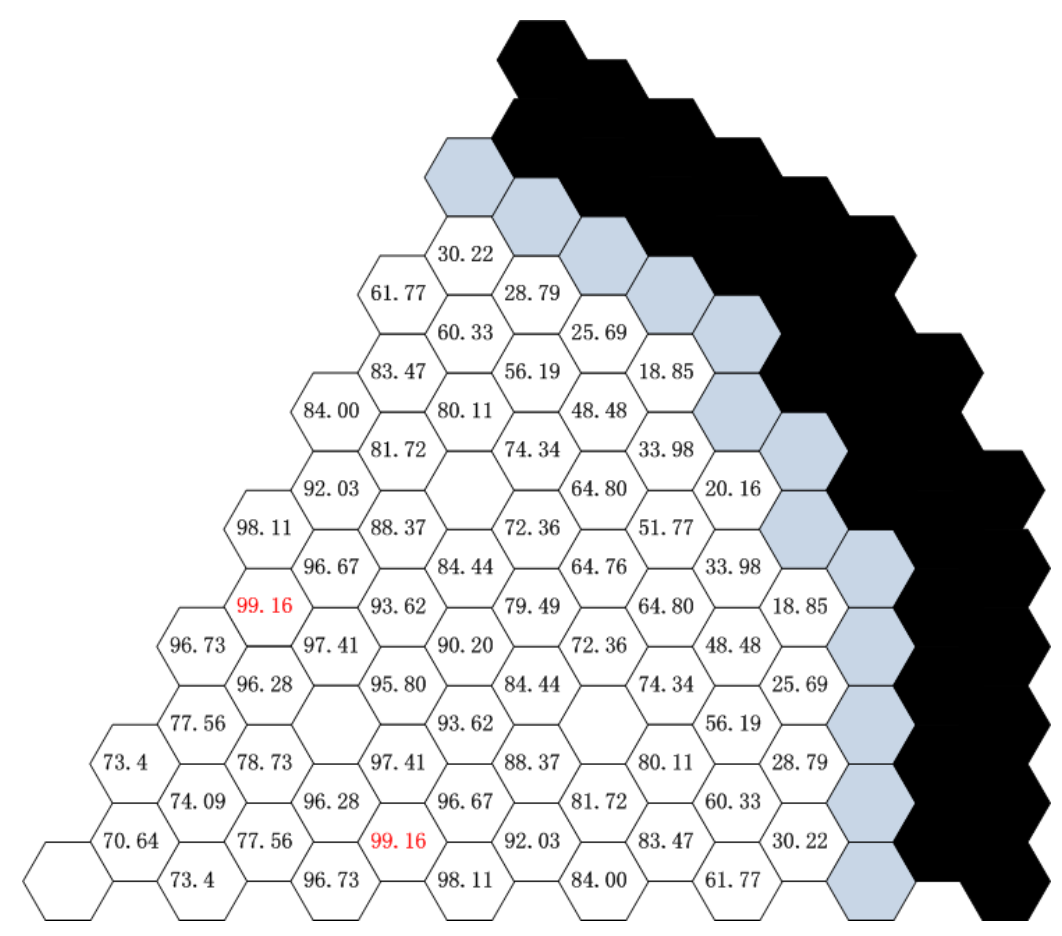

Fig. 11. Burnup distribution $\left(1 / 6^{\text {th }}\right.$ core, GWd/tHM)

\subsection{Reactivity coefficient}

In the event of a LOCA in a gas-cooled reactor, depressurization would happen rapidly and so the coolant void worth is conservatively taken to be the difference in reactivity between fully pressurized and ambient pressure in the primary coolant system. In a fast reactor, there are several competing neutron effects of voiding coolant: spectral effects, coolant absorption effects and leakage effects. Firstly, the spectral effects result from the loss of moderation by coolant atoms and subsequent hardening of the neutron flux spectrum. This change in neutron energy tends to lower parasitic capture cross-sections, but also lowers fission cross-sections giving two competing effects on reactivity during a LOCA. However, this effect is more pronounced with liquid metal coolant than gas coolant because of the higher density of liquid metal coolant. Secondly, the coolant absorption effect of voiding serves to increase the coolant void reactivity in a LOCA. But this effect is also more important in liquid metal cooled reactors and has a very small effect in gas 
cooled reactor. Finally, the core neutron leakage is the main effect to be considered in the study.

In the study, the coolant void reactivity effect is evaluated by assuming the rapid depressurization during which the coolant density (about $0.1 \mathrm{~g} / \mathrm{cc}$ ) decreases to $0.002 \mathrm{~g} / \mathrm{cc}$ (Pope M.A., 2006). The Doppler coefficients are calculated at the fuel temperature of $1000{ }^{\circ} \mathrm{C}$ (changing $\pm 20{ }^{\circ} \mathrm{C}$ ). The coolant void reactivity and Doppler coefficient results are shown in Table 5. As the core operation time accumulates, the burning zone moves into the core center. Thus, the neutron leakage effect decreases. As a result, the $\mathrm{S}-\mathrm{CO}_{2}$ void reactivity increases. However, the $\mathrm{S}-\mathrm{CO}_{2}$ void reactivity and Doppler coefficient are negative throughout the whole core life.

Table 5. Safety features

\begin{tabular}{llll}
\hline \multicolumn{1}{c}{ parameters } & BOL & MOL & EOL \\
\hline Coolant void reactivity, pcm & -555.95 & -237.24 & -11.49 \\
Doppler coefficient, pcm/K & -4.58 & -4.25 & -3.56 \\
\hline
\end{tabular}

Totally 19 control assemblies are adopted in the SMoSC core. The control system is required to have sufficient reactivity worth to bring the reactor from any operation condition to sub-critical state. The reactivity control requirement is estimated by the assumption that the control assembly with the largest worth is stuck out of the active core. In this case, the core multiplication factor with the center control assembly stuck out of the active core is 0.89 at the BOL.

\subsection{Steady-state thermal-hydraulic performance}

The coolant channel diameters and flow allocation are determined through the steady-state thermal-hydraulic analyses. The coolant channel diameters design is one of the main challenges in the SMoSC core design. The coolant channel diameters should make sure that there is no need of refueling the fuel assemblies throughout the core life and the material temperatures satisfy the 
design criteria. The flow rate allocation of the assemblies in each channel is iteratively determined until all thermal-hydraulic design criteria are met.

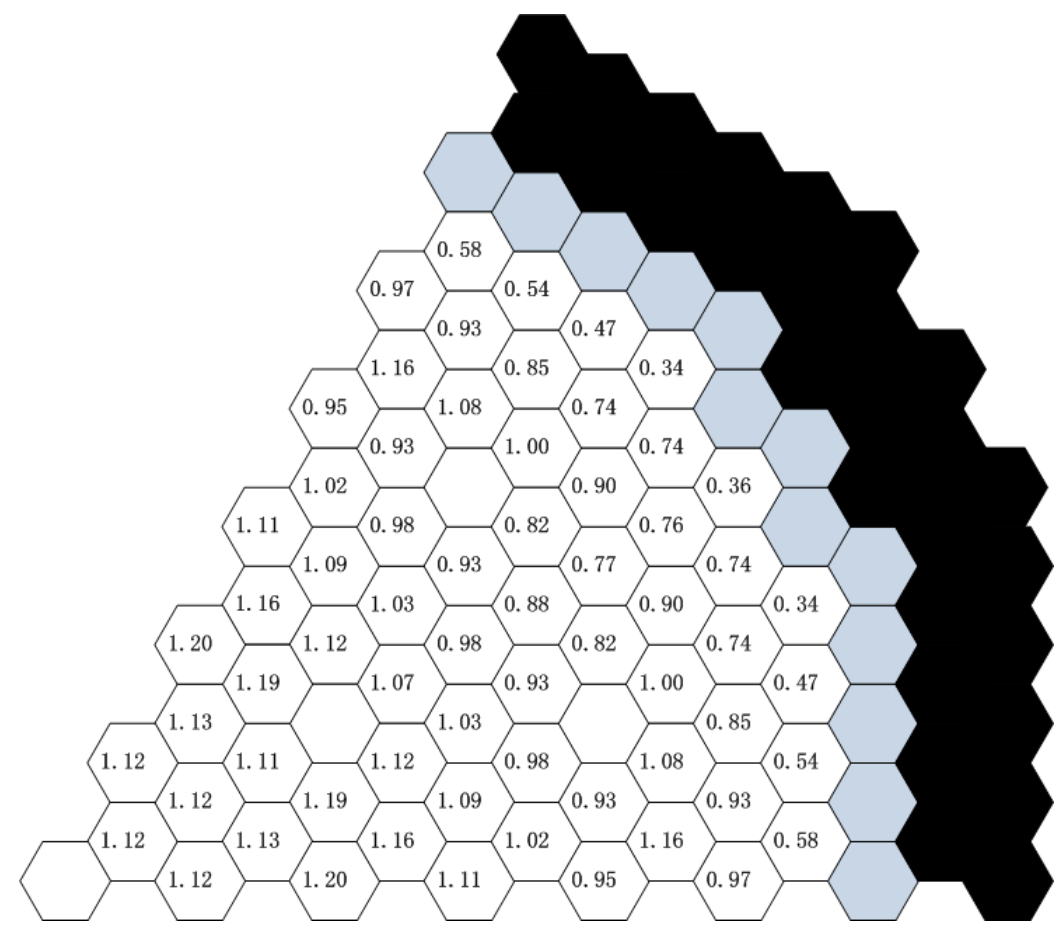

Fig. 12. Normalized coolant flow rate distribution $\left(1 / 6^{\text {th }}\right.$ core $)$

The normalized coolant flow rate distribution is illustrated in Fig. 12. The coolant flow rate in each assembly is searched through the core operation life to satisfy the thermal-hydraulic design criteria. Once the flow rate distribution was obtained, it would not be changed throughout the core life.

It can be seen in Fig. 9 that the inner assemblies make more contributions to generating power and the peripheral assemblies less at the EOL. The inner assemblies need more coolant to remove heat and keep the cladding and fuel temperatures low. The flow rate in the peripheral assemblies is less than that in the inner assemblies, which can be seen in Fig. 12. 


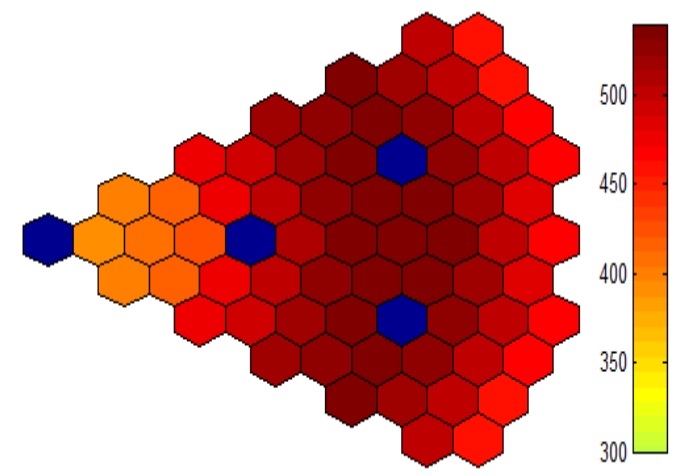

BOL

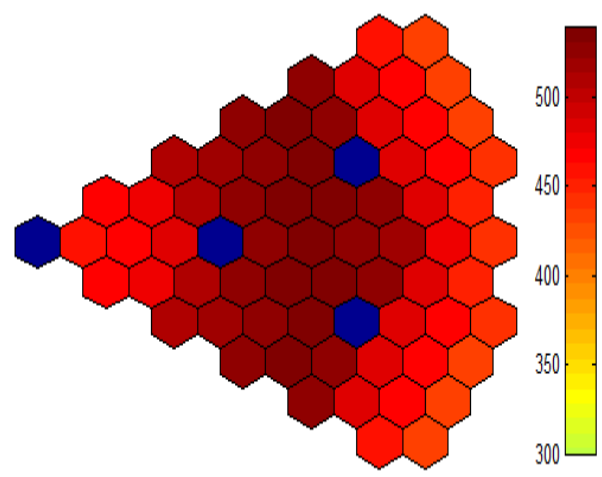

MOL

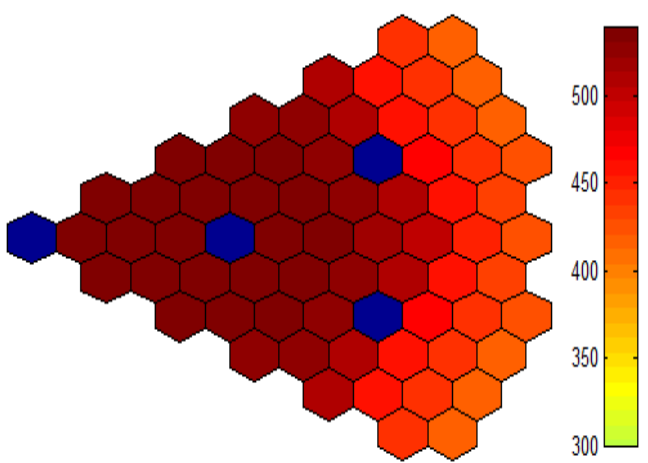

EOL

Fig. 13. Core outlet coolant temperature distributions $\left(1 / 6^{\text {th }}\right.$ core, $\left.{ }^{\circ} \mathrm{C}\right)$

The coolant temperature distributions at core outlet are shown in Fig. 13. At the BOL, the

temperature in the inner regions is lower than that in the outer regions because the inner fuel

regions make less contribution to generating power. With the core operation time increases, the

burning zone moves into the core center, the outlet temperature in the inner regions increases and the outlet temperature in the outer regions decreases.

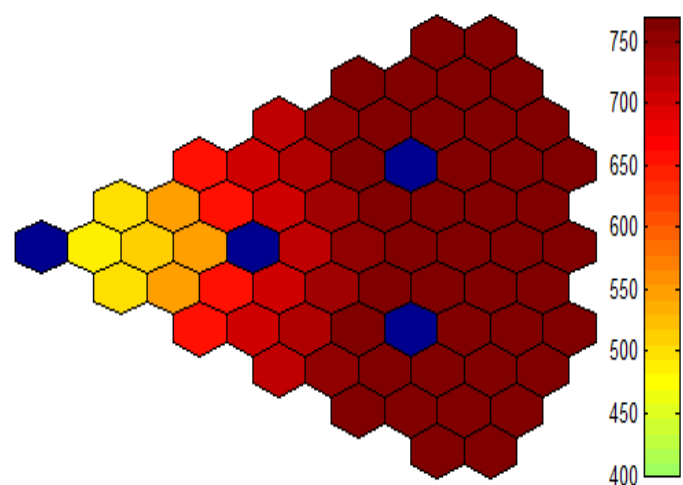

BOL

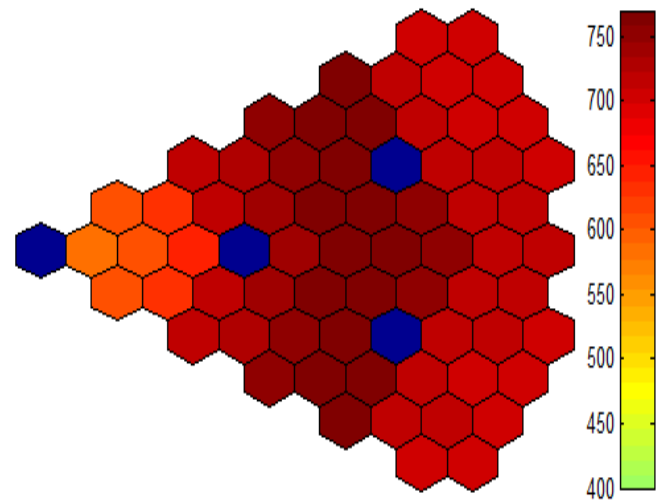

MOL 


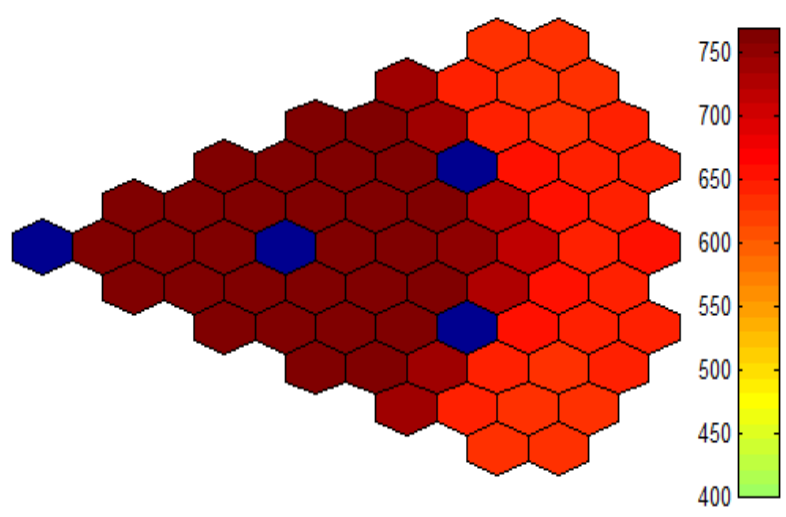

EOL

Fig. 14. Maximum cladding temperature distribution $\left(1 / 6^{\text {th }}\right.$ core, $\left.{ }^{\circ} \mathrm{C}\right)$

The Maximum cladding and Maximum fuel temperatures are also calculated based on the maximum fuel power of the assembly. The cladding temperature distributions are shown in Fig. 14 and the fuel temperature distributions are given in Fig. 15. In order to ensure the integrity of cladding and no melting happens in the fuel, the cladding temperature is limited to be no more than $800{ }^{\circ} \mathrm{C}$ and the fuel temperature is limited to be less than $1800{ }^{\circ} \mathrm{C}$. At the BOL, the peak cladding temperature and the peak fuel temperature both occur in the outer regions. As the burning zone moves, the cladding temperature and fuel temperature in the inner regions increase, but these temperature are still within the material design criteria.

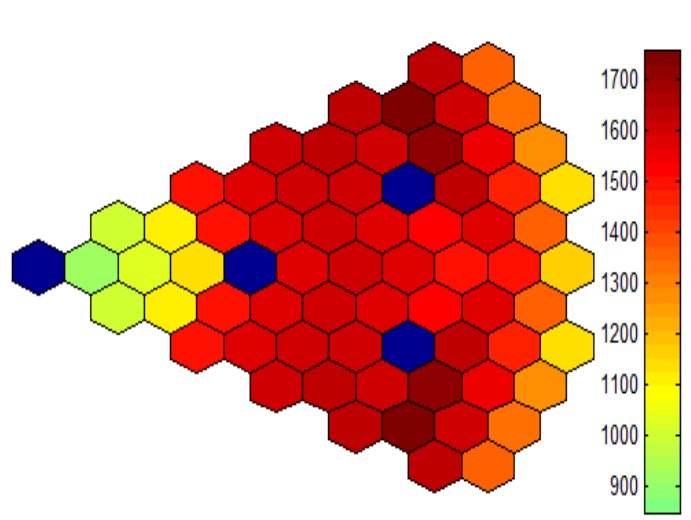

BOL

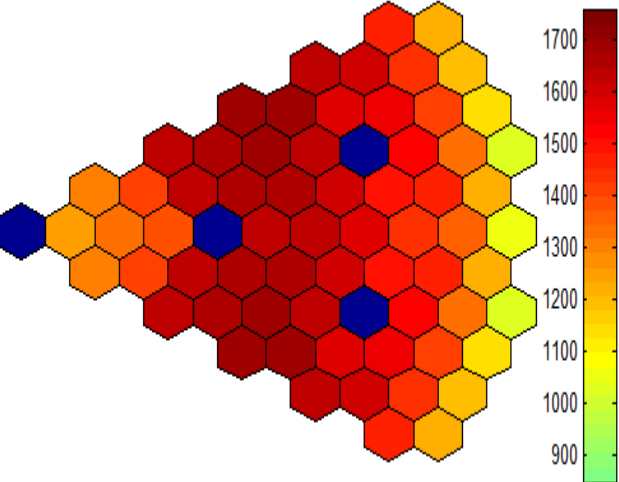

MOL 


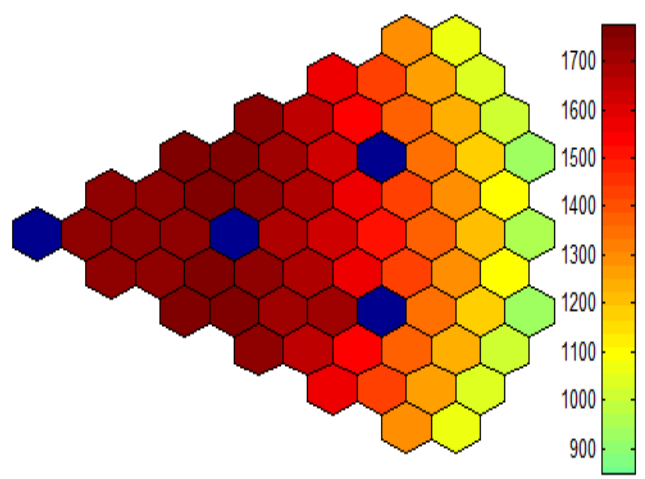

EOL

Fig. 15. Maximum fuel temperature distributions $\left(1 / 6^{\text {th }}\right.$ core, $\left.{ }^{\circ} \mathrm{C}\right)$

The main thermal-hydraulic features are shown in Table 6. With the core inlet and outlet temperatures of $300{ }^{\circ} \mathrm{C}$ and $500{ }^{\circ} \mathrm{C}$, respectively, total coolant flow rate in the active core region is $1245.56 \mathrm{~kg} / \mathrm{s}$. The peaking cladding temperature is $770{ }^{\circ} \mathrm{C}$, while the peaking fuel temperature is $1777{ }^{\circ} \mathrm{C}$. The pressure drop between core inlet and outlet is $373 \mathrm{kPa}$.

Table 6. Thermal-hydraulic features

\begin{tabular}{ll}
\hline \multicolumn{1}{c}{ Parameters } & \multicolumn{1}{c}{ Values } \\
\hline Core inlet temperature $\left({ }^{\circ} \mathrm{C}\right)$ & 300 \\
Core outlet temperature $\left({ }^{\circ} \mathrm{C}\right)$ & 500 \\
Core flow $(\mathrm{kg} / \mathrm{s})$ & 1245.56 \\
Peak clad temperature $\left({ }^{\circ} \mathrm{C}\right)$ & 770 \\
Peak fuel temperature $\left({ }^{\circ} \mathrm{C}\right)$ & 1777 \\
Core pressure drop $(\mathrm{kPa})$ & 373 \\
\hline
\end{tabular}

\section{Conclusions}

In this study, an $\mathrm{S}-\mathrm{CO}_{2}$ cooled small modular fast reactor design with $300 \mathrm{MW}_{\text {th }}$ power output and 20 years' operating period without refueling has been proposed, to target the emerging electricity markets where large scale plant is not feasible. The thermal efficiency is $40 \%$, and the power scale corresponding to an electric output is about $120 \mathrm{MWe}$.

The number of assemblies and assembly parameters are investigated to maximize the refueling interval with minimal burnup reactivity swing. To achieve flat power distribution and 
maintain criticality for a long time, the high leakage fuel loading pattern strategy is employed.

The SMoSC adopted MOX fuel to improve fuel efficiency and obtained smaller burnup reactivity swing due to the high leakage fuel loading pattern strategy. The breeding ratio at the BOL is 1.115 , and the burnup reactivity swing is $872 \mathrm{pcm}$. The specific power density is 9.6 $\mathrm{kW} / \mathrm{kg}$ with the heavy metal inventory of $31.23 \mathrm{t}$, and the average discharged burnup is 70.1 $\mathrm{GWd} / \mathrm{tHM}$ with the peaking discharged burnup of $99.16 \mathrm{GWd} / \mathrm{tHM}$. The reactivity coefficients provide sufficient negative feedback. As the neutron leakage effect decreases throughout the core life, the $\mathrm{S}-\mathrm{CO}_{2}$ void reactivity increases. The coolant void reactivity is $-555.95 \mathrm{pcm}$ at the $\mathrm{BOL}$ but increases to $-11.49 \mathrm{pcm}$ at the EOL. The Doppler coefficient is kept to be negative throughout the whole core life. The peaking cladding temperature is $770{ }^{\circ} \mathrm{C}$, while the peaking fuel temperature is $1777^{\circ} \mathrm{C}$.

This paper has done some preliminary study on the optimization of the coolant void reactivity, cycle length, peaking fuel and cladding temperatures. The $\mathrm{S}-\mathrm{CO}_{2}$ is selected as the radial reflector to ensure the negative the coolant void reactivity. The main parameters of the fuel assembly and the flow allocation are determined to ensure the long refueling interval of the core and satisfy the design criteria. And in order to obtain the sufficient margins of the peaking fuel temperature and the peaking cladding temperature, the power density is derated. The results show that the SMoSC core has favorable safety features. Despite of the above studies, there are still some challenges for this concept to be addressed, including the chemical compatibility between $\mathrm{S}-\mathrm{CO}_{2}$ and structure material, the dynamical properties of the system, etc. In consideration of the overestimate of the neutron leakage at voiding base on the diffusion code, the coolant void reactivity $(-11.49 \mathrm{pcm}$ at EOL) might be insufficient to overcome the calculation uncertainty, study on further reducing the 
coolant void reactivity will be considered in the future. Detailed safety analysis and core control scheme will also be studied in the near future.

\section{Acknowledgments}

This work is financially supported by the National Science Foundation of China (Approved number 91226106), China Postdoctoral Science and Technology Fund (Approved number2013M532051) and Shaanxi Province Postdoctor Science and Technology Fund (Approved number 20130018).

\section{References}

Kessides N., 2012. The future of the nuclear industry reconsidered: Risks, uncertainties, and continued promise. Energy Policy.48,185-208.

Smith R., 2010. Small reactors generate big hopes. Wall Street Journal, p. A1.

VujićJ., Bergmann R.M., Skoda R., et al.,2012. Small modular reactors: Simpler, safer, cheaper? Energy 45, 288-295.

Pope M.A.,2004.Reactor physics design of supercritical $\mathrm{CO}_{2}$ cooled fast reactor.M.S.thesis, Nuclear Engineering Department, MIT.15-84.

Pope M.A.,2006. Thermal hydraulic design of a 2400 MWth direct supercritical CO2 cooled fast reactor. Ph.D.thesis, Nuclear Engineering Department, MIT.14-21, 44-61, 64-65, 89.

Hejzlar, P., Driscoll M.J., Todreas N.E., 2002. The Long-Life Modular Gas Turbine Fast Reactor Concept. International Congress on Adcanced Nuclear Power Plants, Hollywood, Florida.

Handwerk C.S., 2007. Optimized Core design of a Supercritical Carbon Dioxide-Cooled Fast Reactor. Ph.D. thesis, Nuclear Engineering Department, MIT, 30-33, 84-91. 
Angelino G., 1996.Real Gas Effects in Carbon Dioxide Cycles. ASME Paper No. 69-GT-103.

Dostal V., 2004. A Supercritical Carbon Dioxide Cycle for Next Generation Nuclear Reactors.Ph.D.thesis, Nuclear Engineering Department, MIT, 23-39.

Yu K., Driscoll M.J., Yarsky P.J., et.al., 2003. Comparison of GFR Core Reflectors. Trans. Am. Nucl. Soc., Vol. 88.

Feher E.G., 1967. The Supercritical Thermodynamic Power Cycle. Douglas Paper No. 4348, presented to the IECEC, Miami Beech, Florida.

Ashley, S., 2003. Alchemly of a Supermetal. Scientific American, Vol. 289, No. 4.

Waltar, A.E., Reynolds A. B., 1981. Fast Breeder Reactors. Pergamon Press, New York.

Fowler T.B., Vondy D.R., Cunningham, 1971.Nuclear Reactor Core Analysis Code CITATION, ORNL-TM-2496, Oak Ridge National Laboratory.

Peckner, D., Bernstein I.M., 1977. Handbook of Stainless Steels, McGraw Hill.

Kimura, A., Cho G.S., Lee J.S., et.al., 2004. R\&D of Oxide Dispersion Strengthening Steels for High Burn-up Fuel Claddings, Proc. of 2004 International Congress on Advances in Power Plants (ICAPP 2004), Pittsburgh, Pennsylvania, June 13-17.

Okumura K., Kugo T., Kaneko K., Tsuchihashi K., 2007, SRAC2006: A Comprehensive Neutronics Calculation Code System, JAEA-Data/Code 2007-004, Japan Atomic Energy Agency.

Gnielinski, V., 1975. New Equations for Heat and Mass Transfer in Turbulent Pipe and Channel Flow.Forschung im Ingenieurwesen 41, No.1, Federal Republic of Germany. Reprinted in International Chemical Engineering: Translations of the Best in Chemical Engineering, April 1976. 
Chin M.R., Manalo K.L., Edgar C.A., et.al., 2013. OPTIMIZATION OF MULTI-GROUP CROSS SECTIONS FOR FAST REACTOR ANALYSIS. the International Conference on Mathematics and Computational Methods Applied to Nuclear Science and Engineering, Sun Valley, Idaho, May 5-9. 